\title{
LIFE HISTORY, BURROWING BEHAVIOR, AND DISTRIBUTION OF NEOHERMES FILICORNIS (MEGALOPTERA: CORYDALIDAE), A LONG-LIVED AQUATIC INSECT IN INTERMITTENT STREAMS
}

\author{
Matthew R. Cover ${ }^{1}$, Jeong Ho Seo ${ }^{2,3}$, and Vincent H. Resh ${ }^{2}$
}

\begin{abstract}
Several species of fishflies (Megaloptera: Corydalidae: Chauliodinae) have been reported from intermittent streams in western North America, but the life histories and distributions of these species are poorly understood. We studied the life history of Neohermes filicornis (Banks 1903) for 2 years in Donner Creek (Contra Costa County, California), a small intermittent stream that flows for 5-7 months per year. Neohermes filicornis had a 3-4-year life span and larval growth was asynchronous. Analysis of gut contents showed that larvae were generalist predators of aquatic insect larvae including Diptera, Ephemeroptera, and Plecoptera. Final instars dug pupal chambers in the streambed and began pupation within several days of stream drying. Dry conditions in 2007 resulted in stream drying 50 days earlier than in 2006, which was reflected in earlier pupation and adult emergence in 2007 than in 2006. Pupal and adult stages each lasted for 1-2 weeks. Although active burrowing into the dry streambed was not observed in the field, N. filicornis larvae initiated burrowing in response to simulated stream drying in laboratory experiments, while Orohermes crepusculus (Chauliodinae), a fishfly species common in perennial streams, did not exhibit burrowing behavior. We present new and historic collection records for Neohermes spp. in western North America. Neohermes filicornis is distributed in California, Arizona, western New Mexico, Baja California, and Sonora. A sister taxon, Neohermes californicus, has been collected in California, Oregon, and Idaho. In California, N. filicornis is primarily distributed in the Coast Range and mountains of Southern California, whereas N. californicus occurs in the foothills of the Sierra Nevada, with possible range overlap at the northern and southern ends of the Central Valley. As a long-lived aquatic insect, $N$. filicornis exhibits considerable plasticity in the phenology of its life cycle and undergoes multiple episodes of larval dormancy in intermittent streams of western North America.
\end{abstract}

Resumen.-Se han registrado varias especies de insectos (Megaloptera: Corydalidae: Chauliodinae) en los arroyos intermitentes del oeste de América del Norte, pero las historias de vida y la distribución de estas especies son poco conocidas. Durante dos años, estudiamos la historia de vida de Neohermes filicornis (Banks 1903) en Donner Creek (Condado de Contra Costa, California), un pequeño arroyo intermitente que fluye durante 5-7 meses al año. Neohermes filicornis tuvo una esperanza de vida de 3-4 años y el crecimiento de las larvas fue asincrónico. El análisis del contenido intestinal mostró que las larvas son depredadoras generalistas de larvas de insectos acuáticos incluyendo Díptera, Ephemeroptera y Plecóptera. En estadios finales, cavaron cámaras de pupa en el lecho del arroyo e iniciaron la pupación tras varios días en los que el río se secó. Las condiciones áridas del 2007 provocaron que el río se secara 50 días antes que en el 2006, lo que se reflejó en una fase prematura de pupa y el surgimiento de adultos en el 2007 con respecto al 2006. Las etapas de pupa y adulto duraron entre una y dos semanas cada una. Aunque no se observó actividad de excavación en el interior del cauce seco en el campo, las larvas de N. filicornis iniciaron la excavación en respuesta a trazados de secado simulados en experimentos de laboratorio, mientras que Orohermes crepusculus (Chauliodinae), una especie común en arroyos perennes, no presentó un comportamiento de excavación. Presentamos nuevos e históricos registros de la colecta de Neohermes spp. en el oeste de América del Norte. Neohermes filicornis se distribuye en California, Arizona, y en el oeste de Nuevo México, Baja California y Sonora. Un taxón hermano, Neohermes californicus, se ha encontrado en California, Oregón y Idaho. En California, N. filicornis se distribuye principalmente en la cordillera y las montañas del sur de California, mientras que $N$. californicus se encuentra en las estribaciones de la Sierra Nevada, con posible superposición en los extremos norte y sur del Valle Central. Como un insecto acuático de larga vida, $N$. filicornis muestra una plasticidad considerable en la fenología de su ciclo de vida y pasa por múltiples episodios de dormancia larval en arroyos intermitentes al oeste de América del Norte.

Despite the ubiquity of intermittent aquatic habitats in much of western North America, our understanding of the life history characteristics that allow species to persist in these habitats is far from complete (Lytle and Poff 2004). Intermittent stream systems present significant challenges for aquatic biota (Williams 2006), and invertebrates have evolved a variety of life history strategies to avoid or survive dry periods, including rapid larval development (Gray 1981, Wissinger et al. 2003), diapause stages

\footnotetext{
${ }^{1}$ Department of Biological Sciences, California State University, Stanislaus, Turlock, CA 95382. E-mail: mcover@csustan.edu

${ }^{2}$ Department of Environmental Science, Policy, and Management, University of California, Berkeley, CA 94720.

${ }^{3}$ Present address: School of Dental Medicine, University of Nevada, Las Vegas, NV 89106.
} 
(Delucchi and Peckarsky 1989, Shepard and Baumann 1995, Williams 2006), use of the hyperheos (Boulton et al. 1992, del Rosario and Resh 2000, Hose et al. 2005), and migration to upstream or nearby permanent habitats (Meyer and Meyer 2000, Bogan and Lytle 2007, Bogan and Boersma 2012). With climate change and drought already causing changes in the hydroperiod of streams in western North America, an understanding of the adaptations of aquatic species to stream drying is important for the conservation and management of stream communities (Poff et al. 2010).

Several species within the megalopteran family Corydalidae have been reported in intermittent streams in western North America, including representatives of all 4 genera of the subfamily Chauliodinae (fishflies) found in California: Dysmicohermes, Neohermes, Orohermes, and Protochauliodes (Evans 1972, Cover and Resh 2008). Although Dysmicohermes and Orohermes are most commonly reported from perennial streams, the western species of Neohermes and Protochauliodes are found nearly exclusively in intermittent streams (Evans 1972). Additionally, larvae of several species of Corydalus (Megaloptera: Corydalidae) have been reported from intermittent streams in Mexico and the southwestern United States (ContrerasRamos 1998; Michael T. Bogan, U.C. Berkeley, personal communication). Corydalidae possess abdominal spiracles, allowing them to respire atmospheric oxygen, and have also been reported from unusual habitats such as tree holes and purple pitcher plants (Fashing 1994, Hamilton et al. 1996). The larval stages of Corydalidae, known as hellgrammites, are generalist predators of aquatic invertebrates; in some fishless streams, hellgrammites can be the largest and most abundant predators present, and thus play an important role in food web dynamics.

Although life history studies have been conducted for many species of Corydalidae (including Chauliodes rastricornis and Chauliodes pectinicornis in a West Virginia swamp [Dolin and Tarter 1981], Corydalus cornutus in the southern United States [Short et al. 1987, Bowles 1990], Nigronia fasciatus in a West Virgina stream, [Tarter et al. 1975], Nigronia serricornis in Michigan [Petersen 1974], and Protohermes grandis in Japan [Hayashi 1988]), no complete life history studies have been made for any of the species that frequently inhabit intermittent streams in western North America. Evans' (1972) study of the Megaloptera of the western United States remains the most detailed source of information on the life history and distribution of Neohermes and Protochauliodes. He reared several individuals of Neohermes californicus from eggs through the eleventh instar and, based on head capsule widths of field-collected larvae, determined that this species has 12 instars. From field collections made on a single date from an intermittent stream in Lake County, Oregon, Evans estimated that the larval stage of $N$. californicus has a 3-5-year life cycle. In an unpublished thesis, Smith (1970) described the burrowing of first instar $N$. californicus into dry streambeds after hatching, and surmised the species had a 1-year life cycle in intermittent streams near Chico, California.

Little is known about the life history of $N$. filicornis. Larvae of both species of Neohermes are presumed to burrow into dry streambeds and undergo dormancy during the dry season (Evans 1972); however, the details and controls on this behavior are not understood. Likewise, the degree of phenological plasticity of the life cycle in response to annual and seasonal variability in streamflow is unknown.

The objectives of this study are (1) to describe the life history and phenology of $N$. filicornis in relation to streamflow patterns in an intermittent stream in the Coast Range of California; (2) to compare the behavioral responses of $N$. filicornis and Orohermes crepusculus, a hellgrammite common in cold, perennial streams of the Pacific Northwest, to simulated stream drying in a laboratory experiment; and (3) to document the distribution of Neohermes spp. in western North America. We hypothesize that the phenology of N. filicornis is directly related to the timing of flow initiation and cessation in intermittent streams. Consequently, stream drying will provide a cue for larvae to burrow into the streambed and initiate larval diapause. The perennial stream-inhabiting $O$. crepusculus, in contrast, is unlikely to show the same burrowing response to stream drying.

\section{Methods}

\section{Study Organisms}

As an adult, Neohermes filicornis (Banks 1903) is a relatively small (45-55 mm long), 

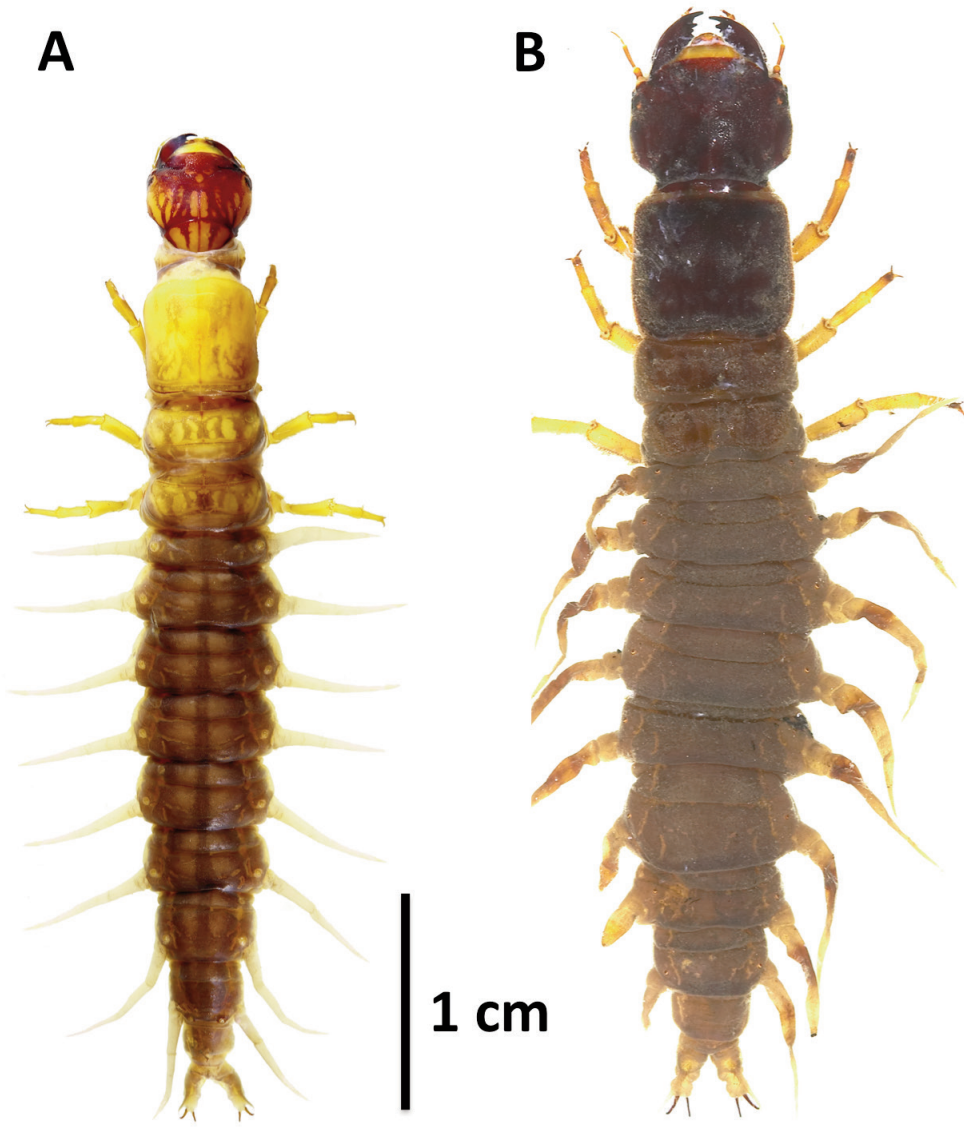

Fig. 1. Mature larvae of Corydalidae used in burrowing experiments: A, Neohermes filicornis; B, Orohermes crepusculus.

gray-colored fishfly. Larvae (Fig. 1), known as hellgrammites, are often found underneath cobble-sized stones in small $(<10 \mathrm{~m}$ wide), intermittent streams in mountainous or hilly regions. Based on collection records, adults emerge from May to October, with a peak in the summer months (Evans 1972). Evans (1972) reported that $N$. filicornis was distributed throughout the California Coast Range as far south as Baja California, and east into Arizona, western New Mexico, and far northern Mexico. A second species of Neohermes in western North America, N. californicus, has been collected primarily in eastern California, with several records from western Nevada, southern Oregon, and Idaho (Flint 1965, Evans 1972, Biggam and Kellar 1998).

Neohermes is believed to be the sister taxon to Protochauliodes, which has a disjunct distribution (western North America, southern South America, and eastern Australia) (Cover and
Resh 2008). There is some evidence that the Protochauliodes lineage may have a Gondwanan origin, with later dispersal to western North America and divergence of Neohermes, suggesting that Protochauliodes may be paraphyletic (Penny 1993, Wang et al. 2012). The other 2 genera of Chauliodinae in western North America, Orohermes and Dysmicohermes, are sister taxa that are endemic to western North America and represent a basal lineage of fishflies that diverged in the early Jurassic (Wang et al. 2012).

Orohermes crepusculus (Chandler 1954), the perennial stream species used in burrowingbehavior comparisons, is a medium to large fishfly (55-65 mm long) widespread in medium to high elevations $(>500 \mathrm{~m})$ of the Pacific Northwest, including the Sierra Nevada and Klamath Mountains of California and the Cascade Mountains of Oregon (Evans 1972). Larvae (Fig. 1) are almost exclusively found 

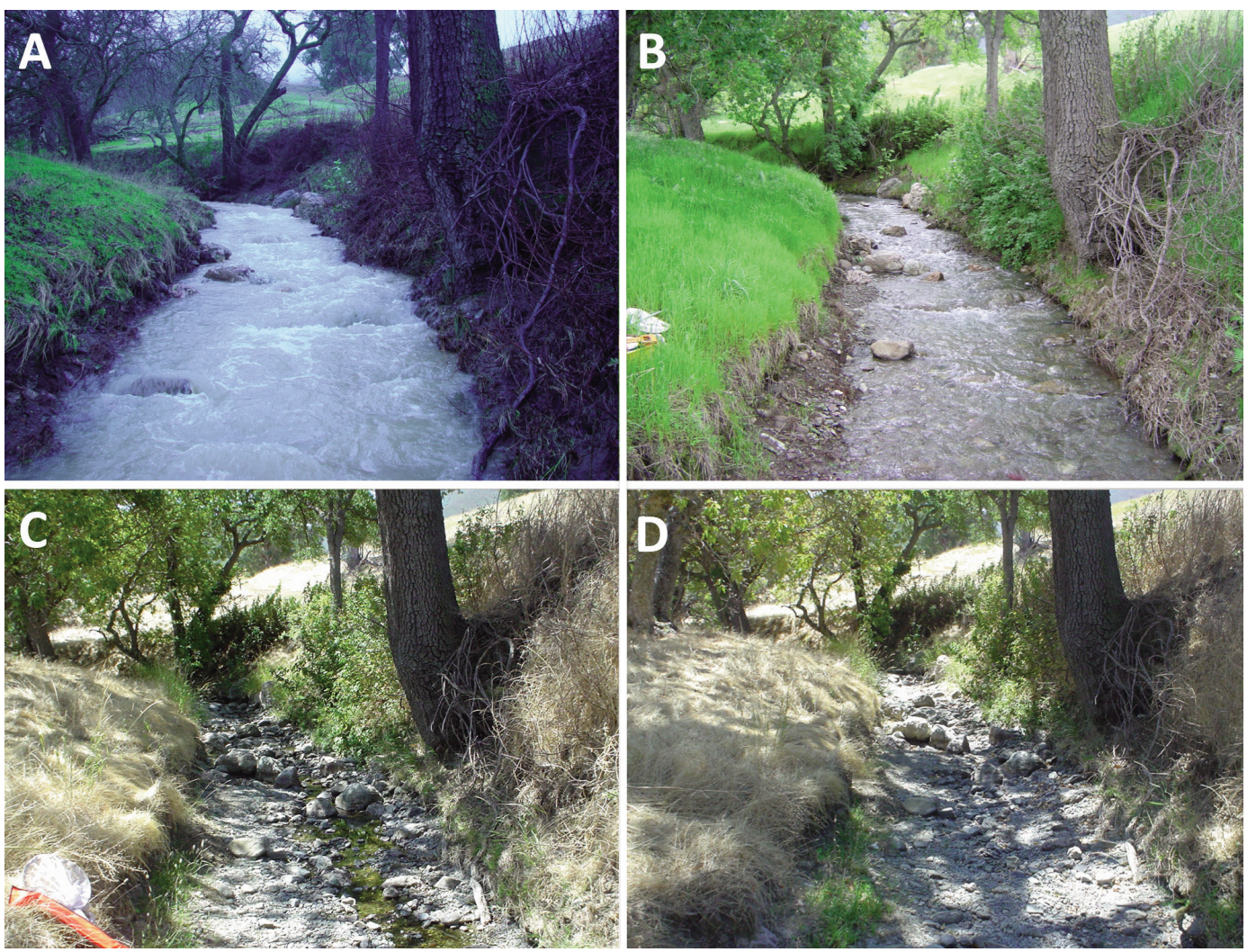

Fig. 2. Sampling reach at Donner Creek during the 2006 water year: A, 02 January; B, 11 April; C, 20 July; D, 6 August.

in steep $(>2 \%)$ cobble-boulder perennial streams, usually in regions where snowmelt dominates the annual hydrograph (Evans 1972).

\section{Study Site}

Donner Creek is a small, second-order stream that drains the undeveloped north flank of Mt. Diablo in eastern Contra Costa County, California (Fig. 2). The study site is a 150-m-long reach located at an elevation of $180 \mathrm{~m}$ near the town of Clayton and the boundary of Mount Diablo State Park $(37.921,-121.927)$. At the study site, the stream has a bankfull width of $1.5 \mathrm{~m}$, a slope of $2 \%$, and a drainage area of $5 \mathrm{~km}^{2}$. Mt. Diablo is located near the eastern edge of the Central California Coast Range, with rocks typical of the Coast Range including Mesozoic sedimentary rocks of the Franciscan and Great Valley assemblages. The region has a Mediterranean climate, with $>90 \%$ of the annual average precipitation of $500 \mathrm{~mm}$ falling between November and April.
Donner Creek is an intermittent stream that usually flows for 5-7 months per year during the winter rain season. In the 20052006 water year (WY06), Donner Creek began flowing on 18 December 2005. A large flood with an estimated return interval of about 5 years occurred on 31 December 2005. Baseflow gradually declined in April and May 2006, and measurable streamflow ceased by 24 July (Fig. 2). By 28 July, the remaining isolated pools had completely dried up. In contrast, the 2006-2007 water year (WY07) was a considerably drier year. Donner Creek began flowing in late-December 2006, ceased flowing in mid-May 2007, and was completely dry by 8 June 2007 . Likewise, in the 2014-2015 water year (WY15), Donner Creek began flowing in early December, ceased flowing in late May, and was completely dry by 4 June 2015. Reduced rainfall in WY07 and WY15 (approximately $300 \mathrm{~mm}$ ) compared to WY06 (approximately $700 \mathrm{~mm}$ ) contributed to the stream drying up approximately 
50 days earlier in WY07 and WY15 than in WY06.

\section{Life History}

Larvae.-Prior to this study, N. filicornis was known only from a small number of localities in the San Francisco Bay Area (Evans 1972). Distribution patterns suggested that populations were limited in extent, small in size, and could be susceptible to local extirpation following changes in habitat or water quality. In order to avoid causing reductions or extirpation of populations, we adopted a conservative sampling approach that minimized the removal and killing of individuals. During WY06 we sampled larvae of $N$. filicornis in Donner Creek every 2-3 weeks when water was present. Larvae were not collected in WY07 for conservation reasons. We used a $500-\mu \mathrm{m}$-mesh D-frame net to collect samples of benthic macroinvertebrates from a total area of $0.56 \mathrm{~m}^{2}$ of riffle and run habitats throughout the $150-\mathrm{m}$ reach. Areas of the streambed that were sampled during one sampling event were not sampled again until a minimum of 2 months had passed. Collected invertebrates were preserved in $95 \%$ ethanol. In the laboratory, samples were examined under a dissection microscope at $10 \times$ magnification, and all $N$. filicornis larvae were enumerated and removed from the sample. The head capsule width (HCW) and total body length (BL) of preserved $N$. filicornis larvae were measured with digital calipers (accuracy, $0.03 \mathrm{~mm}$ ). Because this fixed-area sampling usually resulted in the capture of only a few individuals, we performed 1-2 additional hours of sampling during each field visit until a minimum of 12 additional individuals were collected. Most hellgrammites were collected from the undersides of unembedded, large gravel and cobble-sized stones $(>32 \mathrm{~mm}$ diameter) in shallow water habitats $(<30 \mathrm{~cm}$ depth). We measured HCW and BL in the field using calipers, recorded the coloration of the head capsule, and then released larvae back into the stream.

Size ranges of head capsule widths for each instar were determined from a histogram of HCW of preserved specimens $(n=51)$. In cases where there was not a clear gap or peak in $\mathrm{HCW}$ measurements between successive larvae, existing data on HCW of instars of laboratory-reared Neohermes californicus (Evans
1972) were used as a guideline for determining HCW ranges of $N$. filicornis instars. Plots of HCW and BL of field-measured larvae $(n=$ 189) were also examined, but difficulties in measuring live specimens in the field resulted in substantial HCW measurement error $( \pm 0.1$ $\mathrm{mm}$ ), so this data was considered of secondary importance for instar determination. Although accurate measurements of BL of preserved specimens were made in the laboratory, the relationship between $\mathrm{HCW}$ and $\mathrm{BL}$ of preserved specimens was not examined because larval bodies were found to shrink after preservation. HCW ranges of larvae were used to develop life stage frequency histograms for each sampling date.

PUPAE AND ADULTS.-Prior collection records indicated that adults emerged from May to October, with peak emergence in July. Therefore, we conducted surveys every 2-3 days for larvae, prepupae (i.e., last-instar larvae in a pupal chamber), pupae, adults, eggs, and hatching first instars during the late spring and early summer season. In both WY06 and WY07, we initiated these surveys when measurable streamflow ceased (but isolated pools remained) and completed the final survey 4 weeks after the disappearance of all surface water, or after several visits without observing any pupae or adults. During daylight hours we spent $1 \mathrm{~h}$ searching for larvae, prepupae, pupae, adults, eggs, and first instars by turning over cobble-sized rocks, leaf packs, and terrestrial vegetation in the dry portions of the streambed, banks, and riparian vegetation. Prepupae and pupae were enumerated, and the size and orientation of the pupal chamber was noted. Because of concerns about disrupting the pupal stage, pupae were not handled and HCW and BL were not measured. We also documented the frequency that prepupae and pupae were attacked by ants (Formicidae), the most common invertebrate in the dry streambed of Donner Creek during the late summer and fall seasons. We searched for $N$. filicornis adults for $2 \mathrm{~h}$ after dusk by suspending a portable ultraviolet blacklight in front of a white sheet draped over a tree limb on the stream bank. Adult fishflies that approached the light or sheet were captured by hand or with a sweep net and placed in a 50-mL plastic vial for transport to the laboratory. In the laboratory, adults were placed in a 57-L glass aquarium tank containing assorted 
branches, rocks, and a plastic petri dish filled with water. We made daily observations of adult behavior and documented the length of the adult life stage.

\section{Burrowing Experiment}

In order to compare the behavioral response of the intermittent stream-inhabiting $N$. filicor$n i s$ and the perennial stream-inhabiting $O$. crepusculus larvae to stream drying, we simulated water level lowering in the laboratory. We constructed 16 perforated plastic viewing chambers $(30 \mathrm{~cm}$ depth, $10 \mathrm{~cm}$ length, $1.5 \mathrm{~cm}$ width) that were attached together, end-to-end, in sets of 4 . The narrow width of the chambers was designed to allow for observation of larvae in the subsurface gravels. The chambers were filled to within $3 \mathrm{~cm}$ of the top with gravel and sand (1-3 mm diameter), and placed in a tub filled with stream water to a depth of $2 \mathrm{~cm}$ above the height of the gravel. Larvae were randomly placed in each of the 16 chambers, and the water level was lowered $1 \mathrm{~cm}$ per day. Prior to lowering the water level each day, we observed and documented the burrowing depth, orientation, and behavior of each larva for $15 \mathrm{~min}$.

Two different experiments were conducted in 2007 using this same approach. The first experiment was conducted from 27 March to 29 April with $12 \mathrm{~N}$. filicornis larvae (collected from Donner Creek on 13 March 2007 and 20 March 2007) and 4 O. crepusculus larvae (collected from streams in the Klamath Mountains, California, on 3 February 2007 and 11 March 2007). This experiment was conducted in a refrigerated unit that kept the water at a constant temperature of $15{ }^{\circ} \mathrm{C}$. The second experiment was conducted from 2 August to 29 August 2007 with 8 N. filicornis larvae (collected from various California locations in June and July) and 2 O. crepusculus larvae (collected from streams in the northern Sierra Nevada in July). This experiment was conducted at room temperature $\left(22-25^{\circ} \mathrm{C}\right)$.

\section{Distribution}

We compiled collection data for Neohermes spp. in western North America from the literature, museum and personal collections, bioassessment databases, and field surveys. Literature sources included Flint (1965), Evans (1972), Biggam and Kellar (1998), and ContrerasRamos (1998). We examined specimens from a number of museums and personal collections, including the Aquatic Bioassessment Laboratory (ABL) of the California Department of Fish and Game, Rancho Cordova, CA; the California Academy of Sciences (CAS), San Francisco, CA; the Essig Museum of Entomology, University of California, Berkeley, CA (UCB); the Bohart Museum of Entomology, University of California, Davis, CA (UCD); the Entomology Research Museum, University of California, Riverside, CA (UCR); the National Aquatic Monitoring Center, Utah State University, Logan, UT (USU); and the personal collections of Michael T. Bogan (MTB), University of California, Berkeley, CA; Richard L. Bottorff (RLB), South Lake Tahoe, CA; and Robert W. Wisseman (RWW), Corvallis, OR. We also queried several internet databases of stream macroinvertebrates produced by aquatic bioassessment monitoring programs, including the California Environmental Data Exchange Network (CEDEN; http://www.ceden.org), which includes data produced by the ABL as well as other government agencies, municipalities, private companies, and volunteer groups in California, and the Bug Mapping and Data Retrieval site that contains the database of the National Aquatic Monitoring Center at USU (http://www.usu. edu/buglab). We were only able to obtain and confirm a small subset of specimens that comprised the bioassessment databases, although a number of specimens from unexpected localities were examined and reidentified by the first author. Finally, we included locality data from field surveys of California and Oregon by the first author. All specimen, locality, and collection data is presented in a supplemental appendix as a spreadsheet file hosted with electronic versions of this article (Cover_ et_al_2015_Neohermes.xlsx).

Identification of Corydalidae in the western United States largely depends on Evans' (1972) species key to the adults and larvae. We have found many of these characters to be consistently useful in separating Neohermes and Protochauliodes adults (i.e., antennae of adult male Neohermes are moniliform, whereas Protochauliodes are filiform; gonapophysis lateralis of adult female Protochauliodes with apical papillae, Neohermes without apical papillae). However, the presence of a crossvein in cell R3 of the forewing is not always a reliable character for distinguishing Neohermes 


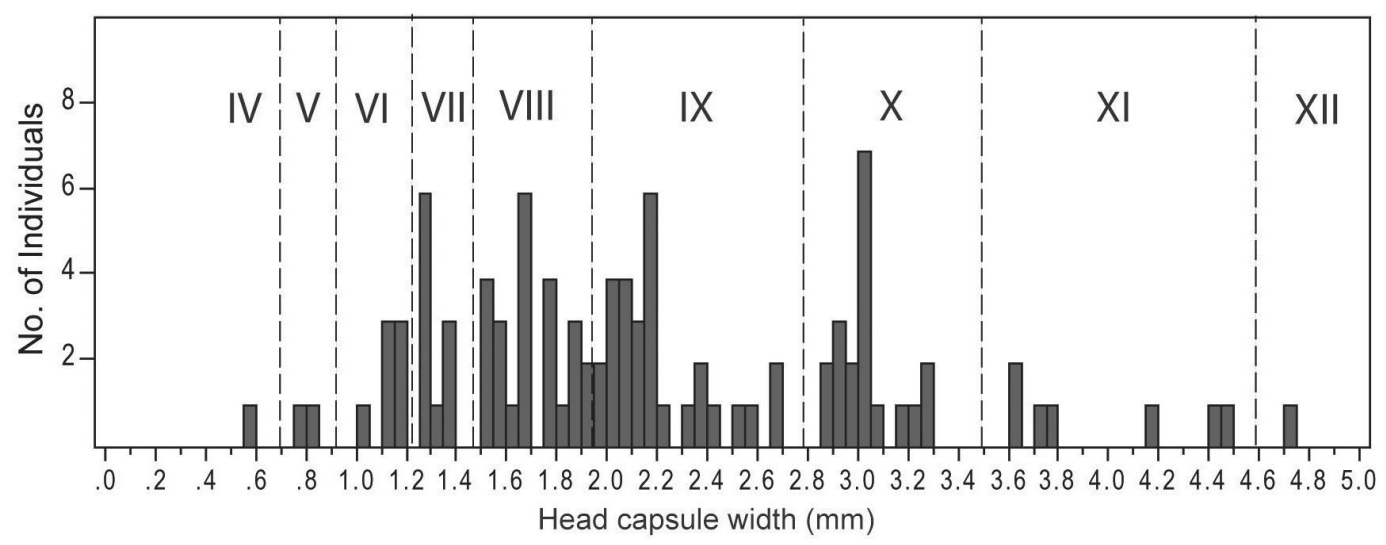

Fig. 3. Histogram of head capsule width (HCW) of preserved Neohermes filicornis larvae from Donner Creek, Contra Costa County, California. Dashed lines and roman numerals indicate estimated instars. Instars I-III were not captured in this study (see Table 1).

and Protochauliodes (Flint 1965, Evans 1972). Adult male Neohermes can be reliably identified by the presence (N. californicus) or absence (N. filicornis) of an apical notch in the genital clasper (Flint 1965, Evans 1972). Females of Neohermes can often be separated by the shape of the genital claspers (apex with a distinct point in $N$. californicus, rounded apically in N. filicornis), although we have observed variation in this character that can make positive species identifications difficult. Larvae of Neohermes and Protochauliodes can be easily separated by the size and shape of the abdominal spiracles on the eighth abdominal segment (Flint et al. 2008), and often by the head pattern (MRC unpublished data). Evans (1972) proposed that larvae of $N$. filicornis and $N$. californicus can be separated by coloration of the abdomen and head, but we have found these characters to be highly variable among instars of the same species and susceptible to changes following specimen preservation in ethanol. For these reasons, we choose to report and map localities of all larval collections of Neohermes spp. at the genus level.

All collection and locality information that we obtained from the sources described above were entered into a spreadsheet database. Collection localities were georeferenced using mapping and geographic tools including Google Maps (http://www.google.com/maps), Google Earth (http://www.google.com/earth), the U.S. Geological Survey Geographic Names
Information System (http://geonames.usgs.gov/ apex/f?p= gnispq), and a variety of paper maps and park guides. For each georeferenced locality we estimated the potential error in our determined location. For example, specimen labels that included the name of a city but no additional identifying information typically were assigned potential error values of several kilometers or more, depending on the size of the city. In contrast, specimen labels that provided information such as a stream and a road intersection allowed for more accurate determinations of the actual collection locale, often to within several hundred meters. We determined the elevation at the collection locality from USGS topographic maps for all locations that were georeferenced with high confidence (typically $<1 \mathrm{~km}$ potential error, depending on local terrain).

\section{REsults}

\section{Life History}

LARVAE.-Larvae of $N$. filicornis appeared on the streambed within 3 days of the rewetting of the stream in winter, and were active throughout the entire wet season. Within several days of stream drying, larvae (except for prepupae) were absent from the surface layer of the streambed. Attempts to find larvae in the dry streambed at depths of up to $0.5 \mathrm{~m}$ were unsuccessful; similarly, larvae were never observed on stream banks or in the riparian zone. 


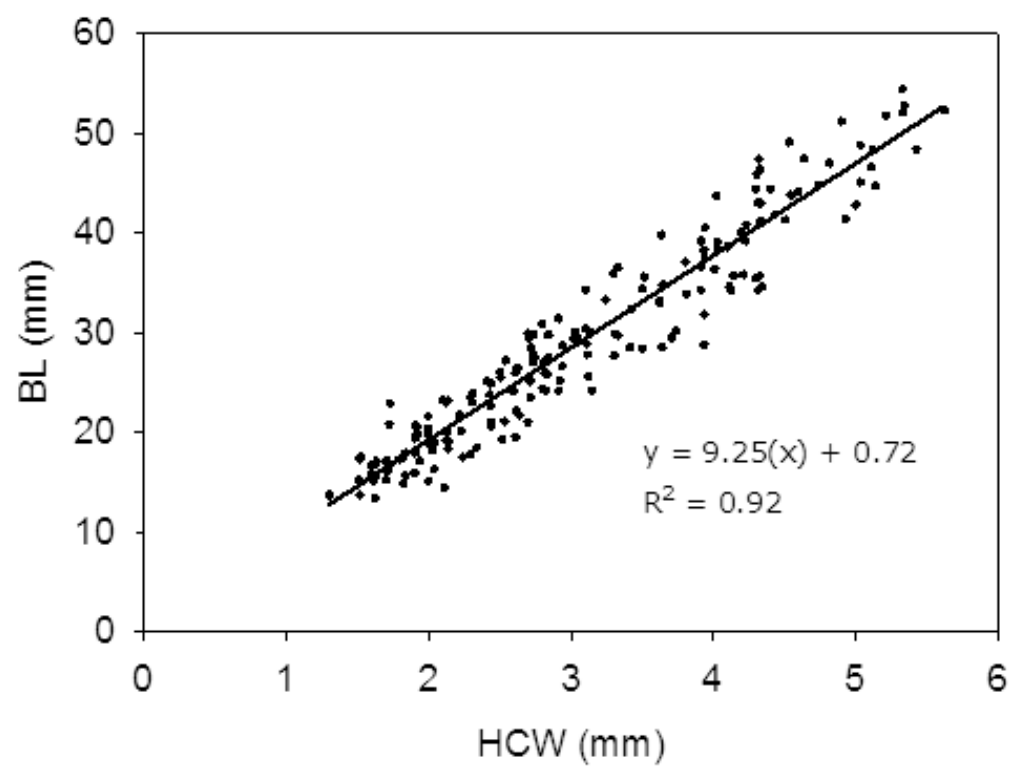

Fig. 4. Relationship between head capsule width (HCW) and body length (BL) of live, field-measured Neohermes filicornis larvae.

TABLE 1. Means (ranges) of head capsule widths ( $\mathrm{mm})$ for instars of Neohermes filicornis (this study) and Neohermes californicus (Evans 1972). ND = not determined.

\begin{tabular}{lcc}
\hline Instar & $\begin{array}{c}\text { N. filicornis } \\
\text { (this study) }\end{array}$ & $\begin{array}{c}\text { N. californicus } \\
\text { (Evans 1972) }\end{array}$ \\
\hline I & ND & $0.3(0.3)$ \\
II & ND & $0.39(0.37-0.4)$ \\
III & ND & $0.47(0.45-0.5)$ \\
IV & $0.56(0.56)$ & $0.61(0.6-0.67)$ \\
V & $0.78(0.75-0.81)$ & $0.77(0.67-0.85)$ \\
VI & $1.14(1.13-1.18)$ & $1.0(0.7-1.1)$ \\
VII & $1.29(1.25-1.38)$ & $1.4(1.3-1.5)$ \\
VIII & $1.70(1.50-1.94)$ & $1.8(1.6-2.0)$ \\
IX & $2.20(2.00-2.69)$ & $2.3(1.8-2.7)$ \\
X & $3.04(2.82-3.25)$ & $3.1(2.6-3.4)$ \\
XI & $3.92(3.30-4.40)$ & $3.9(3.6-4.3)$ \\
XII & $4.97(4.5-5.6)$ & ND \\
\hline
\end{tabular}

Nine instars were identified from the histogram of head capsule widths of fieldpreserved larvae (Fig. 3). Based on mean HCW measurements for each assumed instar (Table 1), the average increase in head size per instar (Dyar's constant) was 1.32 , with a range of 1.13 to 1.46. Field measurements of HCW and BL of live larvae were not useful for identifying instars, although there was a strong linear relationship between the 2 variables (Fig. 4).

Based on previous studies, we believe that the first 3 instars were not collected, likely because the sampling net was too coarse $(0.5$ $\mathrm{mm})$ to retain the early instars (Table 1 ). Instars IV-VI should have been retained by the sampling net but were rarely captured (Table 1, Fig. 3). The last 6 instars (VII-XII) were collected during nearly every sampling event, suggesting a pattern of asynchronous larval development (Fig. 5). Because of this asynchrony, it was not possible to track cohorts through time (Fig. 5).

The coloration of the head capsule of live, field-collected larvae was consistently darker in the later instars than in the earlier instars. The last 2 instars (XI and XII) had a dark reddish-brown, sometimes almost black, head capsule with a bright yellow pattern. The 2 prior instars (IX and X) had orange-brown head capsules with yellow patterns. Fieldcollected larvae of earlier instars had head capsules that were bright orange with a faint yellow pattern (VIII) or pale orange with very faint or no patterns present (VII).

Forty-one percent of guts of $N$. filicornis larvae contained recognizable invertebrate body parts, whereas $18 \%$ were completely empty and $41 \%$ had only unidentifiable material. Prey from 3 insect orders were observed in guts: Ephemeroptera (56\% of prey items), Diptera (37\%), and Plecoptera (7\%). Recognizable Ephemeroptera families were 


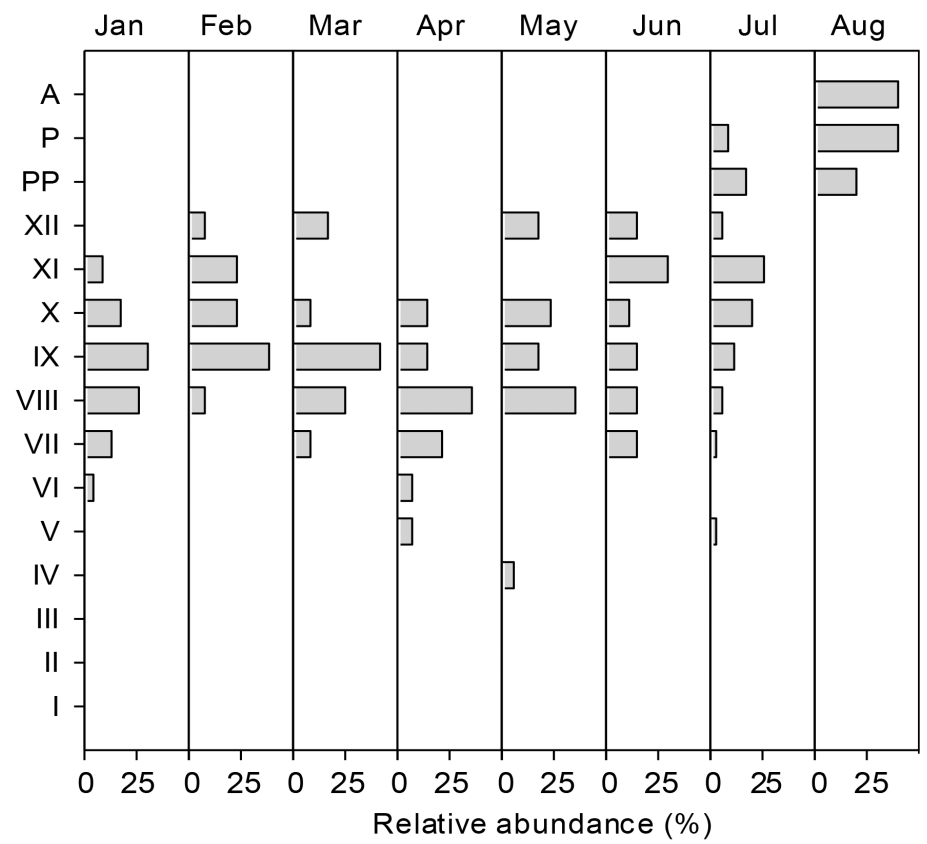

Fig. 5. Relative abundance $(\%)$ of instars I-XII, prepupae (PP), pupae (P), and adults (A) of Neohermes filicornis by month in 2006. Note that eggs and instars I-III were never collected, and no individuals were collected SeptemberDecember.

Baetidae and Heptageniidae; recognizable Diptera families were Simuliidae and Chiromomidae. The average gut fullness was 1.8 (on a scale of 0-4). Average fullness was significantly greater (2.2) in guts from spring and summer (24 March to $20 \mathrm{July} ; n=15$ ) than from the winter (1.1) (2 January to 14 March; $n=11)(t$ test: $P=0.03)$.

PuPAE AND ADUlTs.-Pupae were found over a 2-3 week period in both 2006 and 2007 , but the timing of the pupal stage varied between the 2 years. In 2006, pupae were observed from 28 July to 17 August, a 3-week period immediately following the complete drying of the streambed. In 2007, pupae were observed from 8 June to 25 June (about 50 days earlier than in 2006), a two and a half week period immediately subsequent to the complete drying of the streambed. Based on the timing of the appearance of the first adults (see below), the duration of the pupal stage was approximately 2 weeks. Prepupae and pupae were always observed in pupal chambers underneath large rocks (b-axis diameter, 90-250 mm) in the dry streambed that were $15 \%-50 \%$ embedded by sand and fine gravel $(<4 \mathrm{~mm})$ (Fig. 6). Pupal chambers were oval-shaped, 18-65 mm long, 10-30 mm wide, and 15-30 mm deep (Fig. 5B). Pupal chambers were most commonly (70\%) located under the downstream end of rocks, and were located 15-50 mm below the elevation of the surface of the streambed. Most chambers $(90 \%)$ occurred singularly under a rock, although pairs of chambers were occasionally (10\%) found. Larval exuviae were often observed in the pupal chambers. Several chambers were empty, presumably because adults had emerged.

Ants were swarming over pupae in approximately one-third of occupied burrows. Live pupae being attacked by ants were wriggling and thrashing their bodies. Dead pupae that apparently had succumbed to ant attacks were also observed.

Fifteen adult males were field collected, but no females were collected in the field. Like the pupae, adults were collected over different 2-3-week periods in both 2006 and 2007. In 2006, adults were collected from 10 August through 31 August, and were most abundant on August 10. In 2007, adults were collected between 30 June and 14 July (about 45 days earlier than in 2006). Adults died 1-10 


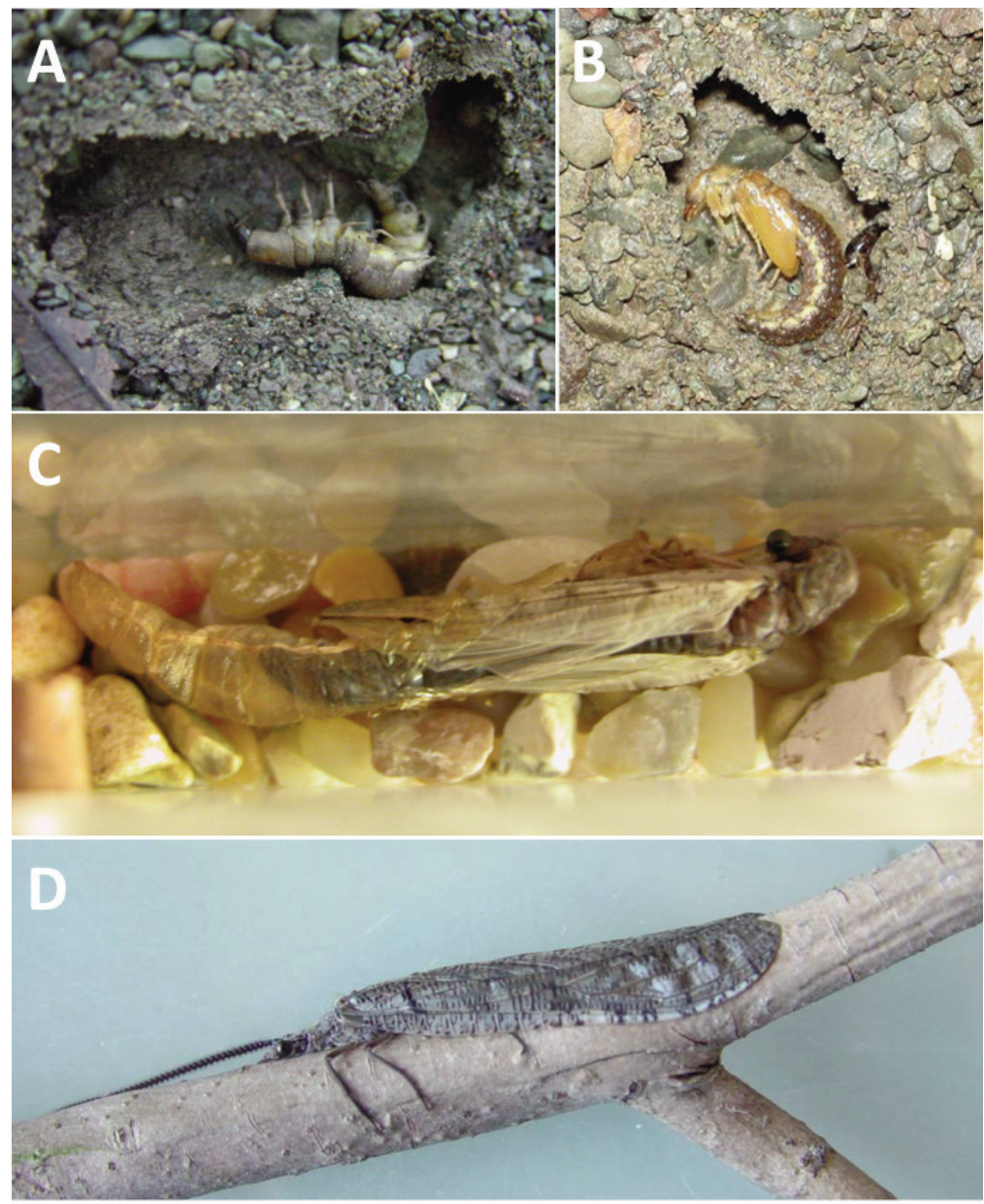

Fig. 6. Neohermes filicornis life stages: A, Prepupa in a pupal chamber in Donner Creek; B, pupa and larval exuvia in a pupal chamber in Donner Creek; C, emergence of an adult female in a laboratory burrowing chamber; $\mathbf{D}$, adult male clinging to a branch in a laboratory aquarium.

days after collection. One female that was reared from the larval stage lived for 14 days as an adult in the laboratory (Fig. 6). Adults were collected only at night at the blacklight (approximately $1.5 \mathrm{~h}^{-1}$ ), and were never observed during the day. Adults often fluttered near the blacklight for a few seconds before coming to rest on a nearby tree branch. On several occasions adults were clinging to small branches with their legs and wings wrapped around the branch and their antennae extended parallel to the branch (Fig. 6). This clinging behavior was observed both in the field and in the laboratory.

Egg masses and first instars were not found, despite numerous hours we spent searching the surface of the dry streambed, stream banks, and riparian vegetation.

\section{Burrowing Experiment}

In the 2 experiments, $85 \%$ (17 out of 20 ) of the $N$. filicornis larvae burrowed at least $0.5 \mathrm{~cm}$ deep, whereas none $(0$ of 6$)$ of the $O$. crepusculus larvae showed any evidence of burrowing behavior. The average burrowing depth of $N$. filicornis larvae was $2.0 \mathrm{~cm}$, and the maximum burrowing depth was $3.5 \mathrm{~cm}$. Larvae that burrowed began burrowing 2-5 days after the water level was lowered beneath the top of the gravel. Approximately one half of the larvae stayed in place after the initial burrowing attempt, whereas others burrowed 


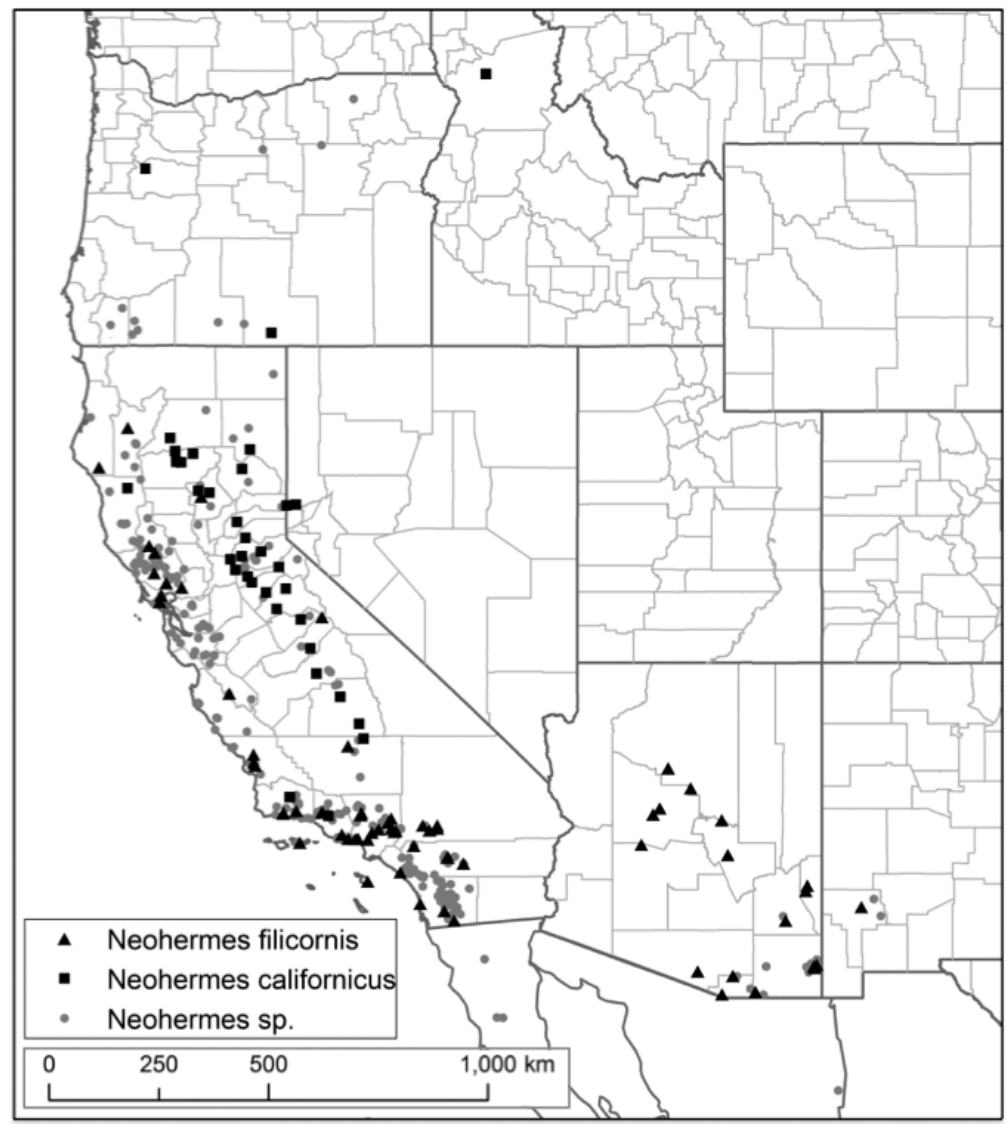

Fig. 7. Georeferenced collection records of Neohermes in western North America.

up and down several times during the experiment. Survival during the experiments was high $(>90 \%)$.

Active burrowing behavior of $N$. filicornis was observed on several occasions. Larvae picked up small pieces of gravel (1-3 mm diameter) between their 2 mandibles, rotated their bodies, and then dropped the stone. Larvae also pushed sand and gravel pieces with the dorsal side of the head. The legs were not used for grasping or pushing sediment. Unlike $N$. filicornis pupal chambers, which were usually substantially larger than the body size of the pupa, larval burrows were not larger than the body size of the larvae.

Orohermes crepusculus larvae never exhibited burrowing behavior and were always observed in a horizontal position on the top of the gravel, often with the head slightly raised upward. Larvae were rarely active, often remaining in the same position for many consecutive days.

\section{Distribution}

We documented 84 collection records of $N$. filicornis, 37 records of $N$. californicus, and 372 records of undetermined Neohermes specimens (mostly larvae) from western North America (Fig. 7). Neohermes filicornis was collected in California (58 localities), Arizona (25), and New Mexico (1). Neohermes californicus was primarily collected in California (32), with several records from western Nevada (2), Oregon (2), and Idaho (1). Additionally, Neohermes larvae (likely $N$. filicornis) have been collected in Baja California and Sonora. Within California, N. filicornis is primarily distributed in the Coast Ranges of Northern and Central California, and the Transverse and Peninsular Ranges of Southern California; N. californicus is primarily found in the foothills of the Sierra Nevada (Fig. 7). Neohermes has been recorded in all but 12 of California's 58 counties: Del Norte and Siskiyou Counties in northwestern 
California; Glen, Kings, Merced, San Joaquin, Yolo, and Yuba Counties in the Central Valley; Imperial, Inyo, and Mono Counties at the eastern edge of the state; and in the City and County of San Francisco. Mean elevation of collection localities of Neohermes (presumably all $N$. filicornis) was higher in Arizona and New Mexico (1686 m) than N. filicornis localities in California $(603 \mathrm{~m})$ and $N$. californicus localities in California $(350 \mathrm{~m})$.

\section{Discussion}

\section{Life History}

Comparison of the HCW of field-collected specimens to laboratory-reared specimens of N. californicus (from Evans 1972) suggests that the first 3 instars were not collected in the field and that $N$. filicornis had 12 instars (Table 1, Fig. 3). Because neither eggs nor the putative instars I-III were collected in the field, it was impossible to track the growth of the youngest cohort through time. Instars IV-VI were infrequently captured, probably because of the relatively short duration of these instars. Evans (1972) found that the duration of instars III-VI of laboratory-reared $N$. californicus was fairly short (11-15 days per instar), whereas instars IX-XI each lasted for 1-3 months. By instar VII, at the latest, larval development in our study was highly asynchronous, as evidenced by the presence of instars VII-XII throughout the year. This suggests that larval growth rates are highly variable, perhaps as a result of the combination of patchy food resources, relatively immobile larvae, and localized differences in the timing of stream drying and rewetting. For example, we never observed exposed larvae on the streambed; larvae were only found underneath large rocks. Likewise, radio-tracking studies of Protohermes grandis, a dobsonfly common in Japan, showed that larvae remained relatively motionless for weeks at a time, acting as sit-and-wait predators (Hayashi and Nakane 1989).

Gut contents indicate that $N$. filicornis larvae are opportunistic predators of aquatic insects. The 3 insect orders that were consumed by larvae (Ephemeroptera, Plecoptera, and Diptera) make up the vast majority of invertebrates in the benthos in Donner Creek. In particular, Baetidae and Chironomidae were the most commonly identified families in $N$. filicornis guts and the most abundant benthic invertebrates in Donner Creek.

Gut fullness was greater in the spring and summer than in the winter. Although $N$. filicornis larvae were present within several days of stream rewetting, prey availability may initially be limited because many insect taxa did not appear for several months after rewetting. High flows during the winter season may limit prey availability and predation success, whereas invertebrate prey are likely to be more plentiful as flows diminish during the late spring and summer. Smith (1970) observed N. californicus larvae consuming large numbers of aquatic invertebrate prey that were left stranded as isolated pools dried up. High spatial and temporal variability in prey availability is likely an important factor contributing to variability in growth rates of larvae from the same cohort.

We observed substantial changes in head capsule coloration among instars, with later instars having darker colors and more visible patterns; early instars (I-VII) often completely lack visible patterns on the head capsule. These trends in coloration are complicated by the fact that it takes 1-2 days following a molt for pigments to darken to normal colors. Additionally, colors can fade after specimens are preserved in ethanol. Our observations suggest that caution should be taken in using patterns and colors of the head capsule for taxonomic identification purposes, especially for smaller larvae (Evans 1972, Flint et al. 2008). Instead, we recommend the use of the spiracles on abdominal segment VIII, which are unique among all genera of Corydalidae in North America, as well as morphological characters such as the shape of the gena (curved in Neohermes and Protochauliodes, angular in Orohermes and Dysmicohermes) as diagnostic characters.

The population of $N$. filicornis in Donner Creek clearly had a life cycle of longer than 1 year, but the length of the life cycle is uncertain and likely varies among individuals within a cohort. We believe that Smith's (1970) estimate of a 1-year life cycle for $N$. californicus in intermittent streams near Chico, California, is incorrect and was based on insufficient sampling. Based on the occurrence of instar IV in late May and instar V in early July, and the duration of instars of $N$. californicus given in Evans (1972), it seems reasonable that some of 
the faster-growing members of the cohort of first instars that hatched the previous summer would have reached instar V or VI prior to summer diapause at the end of their first year. As mentioned above, the duration of instars III-VII may be very short, resulting in substantial asynchronicity if growth rates are variable (Fig. 5). By the end of their second year, fast growers could be instar $\mathrm{X}$, whereas slow growers may only be instar IX. In this scenario, some larvae would reach maturation by the end of their third year, whereas others might take a fourth year. Similarly, Evans (1972) estimated a 3-5-year life cycle for $N$. californicus in an intermittent stream in Oregon that flowed for 9 months per year. Given the constraints on growth placed by the summer dry period, life cycles are expected to vary greatly with local hydrologic conditions, and could be $>5$ years in streams with $<3$ months of streamflow per year.

The streambed drying process is an environmental cue for either pupation (for final instars) or burrowing into the streambed (for all earlier instars). This relationship was consistent in 2006 and 2007, even though less precipitation in 2007 resulted in the stream drying 50 days earlier than in 2006. Attempts to find larvae in the dry streambed during the summer were unsuccessful; however, we believe larvae must burrow rapidly into the drying streambed and then enter a diapause or quasidiapause state (with very low metabolic expenditure) during the dry season. Observations of larval burrowing during laboratory experiments (discussed below) confirm that stream drying is a cue for burrowing.

Like other fishflies that primarily inhabit intermittent streams in western North America (i.e., Protochauliodes spenceri, N. californicus; Evans 1972), N. filicornis created pupal chambers in the dry streambed. Pupation in the streambed likely reduces the risk of predation during an energetically costly migration away from the stream to the banks or riparian zone. The timing of pupation relative to streambed drying is critically important for the survival of $N$. filicornis, and may represent a tradeoff between the risks of mortality if pupation occurs too early or too late. If pupation begins when water is still present at the surface or near the subsurface of the stream, pupae run the risk of fungal infections. Evans (1972) documented $50 \%$ mortality from fungal infections among pupae collected from wet pupal chambers. However, if pupation is too late, predation by terrestrial predators may result. For example, within 3 days of complete drying the streambed was dominated by ants (Formicidae), terrestrial woodlice (Oniscidea), and spiders (Araneae). We documented a high rate of pupal mortality (approximately 33\%) as a result of ant attacks. Other studies have documented terrestrial invertebrates (e.g., ants, beetles) that prey on aquatic insects that are stranded as streams recede or dry up (Stanley et al. 1994, Williams 2006). Mortality as a result of terrestrial predators likely increases with time following streambed drying as the terrestrial arthropod community becomes more established.

Synchronous local emergence of adults is ensured by the synchronous initiation of pupation as a result of streambed drying. Nearby streams that consistently dry up at different times of the year (i.e., at least one month apart), however, may present a barrier to gene flow between populations because of the short length of pupal (1-2 weeks) and adult (1-2 weeks) life stages. Perhaps as a consequence of potential spatial variation in the timing of streambed drying, adults stay near their larval habitat and are almost exclusively found alongside streams (Evans 1972).

Collection records from museums indicate a biased male to female sex ratio (2:1), although this ratio is not nearly as extreme as we observed in this study (15:0). We believe it is possible that males are collected more frequently because they are more active. Evans (1972) reported that $N$. californicus females in the laboratory tended to stay in place, waiting for males to locate them and begin copulation.

Streambed drying is the environmental cue for terminal instars to begin pupation, resulting in synchronous emergence of adults. Because the pupal and adult stages of $N$. filicornis are highly synchronous, the eggs and first instar larvae should be synchronous as well. We did not observe eggs or first instars at our study site despite extensive searching; we remain confounded as to where oviposition occurs. However, Evans (1972) reported that female $N$. californicus laid eggs "beneath large flat rocks in the dry streambed" and that first instars hatch in about 2 weeks and "crawl into the cracks and crevices of the dry streambed." Winter storms usually result in rapid rewetting 
of the entire stream channel, which should result in uniform timing of cessation of diapause among the first instars.

\section{Burrowing Behavior}

The results of the laboratory experiments support the hypothesis that $N$. filicornis responds to stream drying by burrowing into the dry streambed, while $O$. crepusculus does not exhibit this behavioral response. Burrowing behavior, or lack thereof, reflects the current ecological niches occupied by the 2 species: $N$. filicornis is commonly found in intermittent streams, while $O$. crepusculus occurs almost exclusively in perennial, high-elevation streams fed by snowmelt.

Very low soil moisture was apparent within $0.5 \mathrm{~m}$ of the streambed surface in Donner Creek during the summer, suggesting that larvae must burrow at least this deep in order to remain in a moist environment. Burrowing depths in the laboratory experiments were much shallower than this, however, and may have been a result of unnatural experimental conditions. The artificial streambed in the burrowing chambers remained moist for much of the experiment, which may have limited the burrowing depth of $N$. filicornis larvae. Once they burrowed, however, about half of the larvae did not move for the duration of the experiment, suggesting they were in diapause. Other larvae moved back to the surface and reburrowed several times, perhaps reflecting the semiwet conditions of the experiment.

\section{Distribution}

Neohermes has been collected in 6 states in the western USA and 2 states in western Mexico, but the vast majority of collection records are from California. Neohermes filicornis has a more coastal and southerly distribution, whereas $N$. californicus has a more northern and interior distribution, with California's Central Valley largely separating the range of the 2 species. However, several specimens of the coastal species $N$. filicornis have been collected in the foothills of the Sierra Nevada at the northern and southern ends of the Central Valley, and there is one record of N. californicus from the northern Coast Range. Thus, areas of apparent range overlap occur (1) at the north end of the Sacramento Valley, where the foothills of the Sierra Nevada are nearly contiguous with the southern Cascade Moun- tains, the eastern Klamath Mountains, and the eastern portion of the Coast Range; and (2) near the southern end of the San Joaquin Valley, where the foothills of the southern Sierra Nevada meet with the Transverse Range and the southern Coast Range. Further collecting of adult specimens in these 2 locales, and subsequent phylogeographic analysis, could clarify the distribution and evolutionary history of Neohermes in western North America.

Several gaps in the distribution of Neohermes indicate potential areas of restricted gene flow in western North America. Known populations of $N$. filicornis are separated by approximately $300 \mathrm{~km}$ between coastal Southern California (San Diego/Riverside Counties) and Central Arizona (Maricopa/Yavapai Counties), while $N$. californicus populations are separated by approximately $200 \mathrm{~km}$ between southern Oregon (Jackson/Josephine/Klamath/ Lake Counties) and central/northern Oregon (Linn/Grant/Wasco Counties). Additionally, Neohermes is absent from the floor of the Central Valley of California, a geographic feature about $500 \mathrm{~km}$ long and $50 \mathrm{~km}$ wide. This disjunct distribution likely reflects both the availability of suitable habitat (i.e., small, intermittent streams with gravel and cobble substrate), as well as a greater intensity of collecting in California compared to other western states. We expect that additional sampling in many areas with few or no records, such as central and eastern Oregon, Baja California, and Sonora, will produce additional records of Neohermes. It seems likely, however, that additional collecting will not completely resolve the disjunct distribution of Neohermes in western North America. Both California's Central Valley and Imperial Desert lack highgradient, gravel- and cobble-bedded streams with good water quality, and these 2 areas are unlikely to provide suitable habitat. Similarly, extremely high rainfall in northwestern California (i.e., portions of Del Norte, Humboldt, and Siskiyou Counties) and portions of Oregon facilitates widespread perennial flow in mountain streams, which may limit the occurrence of Neohermes. Given these large gaps in the current distribution of both Neohermes species, combined with the species' restricted dispersal abilities, it seems likely that some degree of population-level genetic divergence could have occurred; this hypothesis needs to be tested with a phylogeographic analysis. 


\section{Life History Adaptations to Intermittent Habitats}

Our observations of a population of $N$. filicornis over 2 years indicate that the species exhibits considerable plasticity in its life history in response to the unique hydrologic conditions of a Mediterranean-climate stream. We have collected N. filicornis in other California streams that have as little as 4 months to as much as 9 months of streamflow per year. Neohermes filicornis populations are also present in streams of the Madrean Sky Islands of Arizona and northern Mexico, which flow for $<3$ months per year and occasionally have no streamflow for one full year or more (Bogan and Lytle 2007). Assuming that stream drying serves as the environmental cue for pupation or larval burrowing and dormancy in all of these ephemeral habitats, the phenology of $N$. filicornis must be highly variable in space and time in response to this wide range of hydroperiods.

Rather than considering it a disturbance, seasonal stream drying can be seen as a predictable and expected event (Resh et al. 1988) in the life cycle of $N$. filicornis. Stream drying may, in fact, be an environmental requirement for the life cycle of $N$. filicornis, as there are very few records of the species from perennial streams. If stream drying is the primary environmental cue for pupation, the life cycle might not be completed in streams with perennial flow. Alternatively, if other environmental conditions could serve as cues for synchronous pupation in perennial streams, $N$. filicornis may be absent from perennial streams because of competition from superior predators or predation by fish. It seems likely that $N$. filicornis is adapted exclusively for life in intermittent streams.

As a generalist predator in intermittent streams, $N$. filicornis occupies a unique ecological niche. With the exception of seasonal use of intermittent waters by anadromous fish, aquatic vertebrate predators are generally uncommon in intermittent streams as a result of their relatively long life cycles and intolerance to desiccation (Williams 2006). Similarly, most common predatory aquatic insects in streams have aquatic life cycles that last at least one full year (e.g., Odonata; Coleoptera: Dytiscidae; Plecoptera: Perlidae and Chloroperlidae; Trichoptera: Rhyacophilidae), limiting their occurrence in intermittent habitats unless specific life history adaptations are present.
In Donner Creek, as in most intermittent streams where we have collected $N$. filicornis, there are few or no other aquatic predators present (e.g., Perlodidae). Thus, N. filicornis may play an important role in the food webs of intermittent streams in the study area.

The life history strategies used by N. filicornis in intermittent streams are somewhat unique among aquatic insects. Aquatic insect taxa in intermittent streams often rely upon strategies such as rapid growth, recolonization by aerial adults, recolonization from nearby perennial waters, or survival in isolated pools (Williams 2006). Other taxa diapause in the dry streambed to survive in intermittent streams, most often in the egg stage (e.g., Diptera: Chironomidae and Simuliidae; Ephemeroptera; Plecoptera: Capniidae and Leuctridae) (Gray 1981, Shepard and Baumann 1995, Fritz and Dodds 2004, Williams 2006). Aquatic insects with life cycles of $>1$ year (semivoltine or merovoltine) are more rare in intermittent streams (Gray 1981, Earle 2004), as are large-bodied invertebrates (Chadwick and Huryn 2007). Neohermes filicornis larvae go through multiple episodes of dormancy in response to annual cycles of stream drying.

The life history strategies of $N$. filicornis described in this study raise many interesting questions about evolutionary adaptations to intermittent habitats. Among Megaloptera, species inhabiting intermittent systems have been reported for several genera (Neohermes, Protochauliodes, and Corydalus) in the western United States and northwestern Mexico. Is this region a biodiversity hotspot for ecological strategies and taxonomic diversity of aquatic invertebrates in intermittent aquatic habitats? Intermittent streams are more common than perennial streams throughout much of California and arid western North America. Additionally, a Mediterranean-type climate with wet winters and dry summers has been present in California for at least 3 million years (Axelrod 1977), ample time for the evolution of life history adaptations to predictable annual patterns of stream drying. Dieterich and Anderson (2000) found many unique and previously undescribed aquatic insects in intermittent streams of the Oregon Coast Range. Similarly, many crustaceans and other invertebrates are endemic to vernal pools in California (King et al. 1996). Future life history investigations of aquatic insects in intermittent 
streams of western North America may reveal many more novel and fascinating evolutionary adaptations to annual stream drying.

\section{ACKNOWLEDGMENTS}

We are grateful to the many curators and collectors who arranged loans of specimens for this study and/or provided advice and natural history observations, including N. Anderson (Oregon State University), C. Barr (U.C. Berkeley), R. Blinn (North Carolina State University), M. Bogan (U.C. Berkeley), R. Bottorff (South Lake Tahoe, CA), A. Contreras-Ramos (Universidad National Autónoma de México), E. Dewalt (Illinois Natural History Survey), E. Evans (Michigan DEQ), Z. Falin (Kansas University), O. Flint (Smithsonian Institution), S. Heyden (U.C. Davis), D. Huggins (Kansas University), X. Liu (China Agricultural University), D. Miller (Chico State University), J. Morse (Clemson University), T. New (LaTrobe University), J. Oswald (Texas A\&M University), N. Penny (California Academy of Sciences), B. Richards (CA DFG), T. Schiefer (Mississippi State University), J. Slusark (CA DFG), C. Smith (University of Georgia), I. Stocks (Clemson University), D. Tarter (Marshall University), M. Vinson (Utah State Buglab), R. Wisseman (Corvallis, OR), and D. Yanega (U.C. Riverside). Many undergraduate students assisted with fieldwork, larval measurements, identifying specimens, and georeferencing localities, including R. Chaudhari, B. Lam, J. Lee, M. Riley, and I. Will (U.C. Berkeley), and K. Bailey, H. Cotter, and K. Eng (C.S.U. Stanislaus). Comments from D. Lightfoot and 2 anonymous reviewers greatly improved the manuscript.

\section{Literature Cited}

AXELROD, D.I. 1977. Outline history of California vegetation. Pages 139-220 in M. Barbour and J. Major, editors, Terrestrial vegetation of California. J. Wiley, New York, NY.

Biggam, R.C., AND D.S. KelLaR. 1998. Neohermes californicus (Walker) (Megaloptera: Corydalidae) in Idaho: a new state record. Pan-Pacific Entomologist 74:58.

Bogan, M.T., and K.S. Boersma. 2012. Aerial dispersal of aquatic invertebrates along and away from arid-land streams. Freshwater Science 31:1131-1144.

Bogan, M.T., AND D.A. LYTLE. 2007. Seasonal flow variation allows 'time-sharing' by disparate aquatic insect communities in montane desert streams. Freshwater Biology 52:290-304.
Boulton, A.J., H.M. ValetT, AND S.G. Fisher. 1992. Spatialdistribution and taxonomic composition of the hyporheos of several Sonoran desert streams. Archiv für Hydrobiologie 125:37-61.

Bowles, D.E. 1990. Life history and variability of secondary production estimates for Corydalus cornutus (Megaloptera: Corydalidae) in an Ozark stream. Journal of Agricultural Entomology 7:61-70.

Chadwick, M.A., AND A.D. Huryn. 2007. Role of habitat in determining macroinvertebrate production in an intermittent-stream system. Freshwater Biology 52: 240-251.

Contreras-Ramos, A. 1998. Systematics of the dobsonfly genus Corydalus Latreille (Megaloptera: Corydalidae). Thomas Say Monographs, Entomological Society of America, Lanham, MD. 360 pp.

Cover, M.R., And V.H. Resh. 2008. Global diversity of dobsonflies, fishflies, and alderflies (Megaloptera; Insecta) and spongillaflies, nevrorthids, and osmylids (Neuroptera; Insecta) in freshwater. Hydrobiologia 595:409-417.

DEL Rosario, R.B., AND V.H. RESH. 2000. Invertebrates in intermittent and perennial streams: is the hyporheic zone a refuge from drying? Journal of the North American Benthological Society 19:680-696.

Delucchi, C.M., and B.L. Peckarsky. 1989. Life-history patterns of insects in an intermittent and a permanent stream. Journal of the North American Benthological Society 8:308-321.

Dieterich, M., AND N.H. Anderson. 2000. The invertebrate fauna of summer-dry streams in western Oregon. Archiv für Hydrobiologie 147:273-295.

Dolin, P.S., And D.C. Tarter. 1981. Life history and ecology of Chauliodes rastricornis Rambur and $C$. pectinicornis (Linnaeus) (Megaloptera: Corydalidae) in Greenbottom Swamp, Cabell County, West Virginia. Brimleyana 7:111-120.

EARLE, J.I. 2004. Stonefly (Plecoptera) species of an acidic intermittent stream in southwestern Pennsylvania, USA, comparison with a circumneutral perennial stream and consideration of survival strategies. Archiv für Hydrobiologie 159:97-114.

Evans, E.D. 1972. A study of the Megaloptera of the Pacific coastal region of the United States. Doctoral dissertation, Oregon State University, Corvallis, OR.

FAshing, N.J. 1994. A novel habitat for larvae of the fishfly Chauliodes pectinicornis (Megaloptera: Corydalidae). Banisteria 3:25-26.

Flint, O.S. 1965. The genus Neohermes. Psyche 72: 255-263.

Flint, O.S., E.D. Evans, and H.H. Neunzig. 2008. Megaloptera and aquatic Neuroptera. Pages 425-437 in R.W. Merritt, K.W. Cummins, and M.B. Berg, editors, An introduction to the aquatic insects of North America. 4th edition. Kendall-Hunt, Dubuque, IA.

Fritz, K.M., AND W.K. DodDs. 2004. Resistance and resilience of macroinvertebrate assemblages to drying and flood in a tallgrass prairie stream system. Hydrobiologia 527:99-112.

GraY, L.J. 1981. Species composition and life histories of aquatic insects in a lowland Sonoran Desert stream. American Midland Naturalist 106:229-242.

Hamilton, R., M. Whitaker, T.C. Farmer, A.A. Benn, AND R.M. DufField. 1996. A report of Chauliodes (Megaloptera: Corydalidae) in the purple pitcher plant, Sarracenia purpurea L (Sarraceniaceae). Journal of the Kansas Entomological Society 69:257-259. 
Hayashi, F. 1988. Prey selection by the dobsonfly larva, Protohermes grandis (Megaloptera, Corydalidae). Freshwater Biology 20:19-29.

Hayashi, F., AND M. NaKane. 1989. Radio tracking and activity monitoring of the dobsonfly larva, Protohermes grandis (Megaloptera, Corydalidae). Oecologia 78: 468-472.

Hose, G.C., P. Jones, and R.P. Lim. 2005. Hyporheic macroinvertebrates in riffle and pool areas of intermittent streams in south eastern Australia. Hydrobiologia 532:81-90.

King, J.L., M.A. Simovich, and R.C. Brusca. 1996. Species richness, endemism and ecology of crustacean assemblages in northern California vernal pools. Hydrobiologia 328:85-116.

LytLe, D.A., AND N.L. Poff. 2004. Adaptation to natural flow regimes. Trends in Ecology and Evolution 19: 94-100.

Meyer, A., AND E.I. Meyer. 2000. Discharge regime and the effect of drying on macroinvertebrate communities in an intermittent karst stream in East Westphalia (Germany). Aquatic Sciences 62:216-231.

Penny, N.D. 1993. The phylogenetic position of Chloroniella peringueyi (Megaloptera: Corydalidae) and its zoogeographic significance. Entomological News 104: 17-30.

Petersen, R.C. 1974. Life history and bionomics on Nigronia serricornis (Say) (Megaloptera: Corydalidae). Doctoral dissertation, Michigan State University, East Lansing, MI.

Poff, N.L., M.I. Pyne, B.P. Bledsoe, C.C. Cuhaciyan, and D.M. CARLISLE. 2010. Developing linkages between species traits and multiscaled environmental variation to explore vulnerability of stream benthic communities to climate change. Journal of the North American Benthological Society 29:1441-1458.

Resh, V.H., A.V. Brown, A.P. Covich, M.E. Gurtz, H.W. Li, G.W. Minshall, S.R. Reice, A.L. Sheldon, J.B.
Wallace, and R.C. Wissmar. 1988. The role of disturbance in stream ecology. Journal of the North American Benthological Society 7:433-455.

Shepard, W.D., AND R.W. BaumanN. 1995. Calileuctra, a new genus and two new species of stoneflies from California (Plecoptera: Leuctridae). Great Basin Naturalist 55:124-134.

Short, R.A., E.H. Stanley, J.W. Harrison, and C.R. EPPERSON. 1987. Production of Corydalus cornutus (Megaloptera) in four streams differing in size, flow, and temperature. Journal of the North American Benthological Society 6:105-114.

SMith, E.L. 1970. Biology and structure of dobsonfly, Neohermes californicus (Walker) (Megaloptera: Corydalidae). Pan-Pacific Entomologist 46:142-150.

Stanley, E.H., D.L. Buschman, A.J. Boulton, N.B. Grimm, AND S.G. Fisher. 1994. Invertebrate resistance and resilience to intermittency in a desert stream. American Midland Naturalist 131:288-300.

Tarter, D.C., W.D. Watkins, and M.L. Little. 1975. Life history of the fishfly, Nigronia fasciatus (Megaloptera: Corydalidae). Psyche 82:81-88.

Wang, Y., X. LiU, S.L. Winterton, and D. Yang. 2012. The first mitochondrial genome for the fishfly subfamily Chauliodinae and implications for the higher phylogeny of Megaloptera. PLOS ONE 7:e40345.

Williams, D.D. 2006. The biology of intermittent waters. Oxford University Press, NY. 348 pp.

Wissinger, S.A., W.S. Brown, and J.E. Jannot. 2003. Caddisfly life histories along permanence gradients in high-altitude wetlands in Colorado (USA). Freshwater Biology 48:255-270.

Received 31 December 2014 Accepted 11 August 2015 